\title{
ANALISIS STRUKTUR GEDUNG IRNA (INSTALASI RAWAT INAP) RUMAH SAKIT UMUM PASAMAN BARAT MENGGUNAKAN SNI BETON BERTULANG 2847:2019 DAN SNI GEMPA 1726:2019
}

\author{
HAMDENI MEDRIOSA, FIKRI AZIDA AKBAR \\ Institut Teknologi Padang \\ hamdenimedriosa@itp.ac.id
}

\begin{abstract}
Indonesia continues to follow the development of building standards in the world which are dynamically changing for the better and safer, both in loading regulations, planning for concrete structures, steel structures, and planning for earthquake resistance. The latest planning standard methods reviewed in this study are SNI-03-1726-2019, SNI-03-2847-2019 and RSNI-03-1727-2020 replacing SNI-031726-2012, SNI-03-1727-2013, and SNI-03-2847-2013. The basic difference in SNI03-1726:2012 compared to SNI-03-1726:2019 is in the coefficients of Fa and Fv, namely the coefficient of soil sites for a long earthquake period of 1 second and in SNI-03-2847:2019 which refers to ACI 318M-14 Building Code Requirements for Structural Concrete. The results of this study found that this change in the modeling of the West Pasaman Regional General Hospital met the requirements for the SNI-O31726-2019 earthquake design and the SNI-03-2847-2019 reinforced concrete design.
\end{abstract}

Keywords: Structural Analysis, SNI-03-2847-2019, SNI-03-1726-2019.

Abstrak: Indonesia terus mengikuti perkembangan standar bangunan gedung di dunia yang secara dinamis terus berubah ke arah yang lebih baik dan aman, baik dalam peraturan pembebanan, perencanaan struktur beton, struktur baja, maupun perencanaan ketahanan terhadap gempa. Metoda Standar perencanaan terbaru yang ditinjau dalam penelitian ini adalah SNI-03-1726-2019, SNI-03-2847-2019 dan RSNI-03-1727-2020 menggantikan SNI-03-1726-2012, SNI-03-1727-2013, dan SNI-03-2847-2013. Perbedaan mendasar dalam SNI-03-1726:2012 dibandingkan dengan SNI-031726:2019 terdapat pada nilai keofesien Fa dan Fv, yaitu keofesien situs tanah untuk periode gempa panjang 1 detik dan dalam SNI-03-2847:2019 yang mengacu pada $A C I$ 318M-14 Building Code Requirements for Structural Concrete. Hasil penelitian ini mendapatkan perubahan pemodelan Rumah Sakit Umum Daerah Pasaman Barat ini memenuhi persyaratan terhadap desain gempa SNI-03-1726-2019 dan design beton bertulang SNI-03-2847-2019.

Kata Kunci: Analisa Struktur, SNI-03-2847-2019,SNI-03-1726-2019.

\section{A. Pendahuluan}

Adanya perubahan SNI 2847-2019 tentang beton bertulang, SNI 1726-2019 Tentang Gempa, RSNI 1729-2020 tentang baja, RSNI 1727-2020 tentang pembebanan menjadi acuan awal dalam mendesign bangunan seusai dengan peraturan yang terbaru. Berdasarkan Undang-Undang Republik Indonesia Nomor 28 Tahun 2002 Tentang Bangunan Gedung. Bangunan gedung adalah wujud fisik hasil pekerjaan konstruksi yang menyatu dengan tempat kedudukannya, sebagian atau seluruhnya berada di atas dan atau di dalam tanah dan atau air, yang berfungsi sebagai tempat manusia melakukan kegiatannya, baik untuk hunian atau tempat tinggal, kegiatan keagamaan, kegiatan usaha, kegiatan sosial, budaya, maupun kegiatan khusus.

SNI-03-1726: 2019 merupakan revisi yang menggantingkan SNI-03-1726:2012. Nilai percepatan respons Spektral Ss dan S1 diperoleh dari peta MCER untuk periode 
pendek 0.2 detik $(\mathrm{Fa})$ dan periode 1 detik $(\mathrm{Fv})$ menghasilkan parameter percepatan respons spektral yang sesuai dengan kelas situs tanah, yaitu SMS untuk periode pendek 0,2 detik dan SM1 untuk periode 1 detik. Nilai percepatan respon spektral desain pada periode pendek, SDS adalah $2 / 3$ dari nilai SMS, dan nilai percepatan respon spektral desain pada periode 1 detik, SD1, adalah 2/3 dari nilai SM1 tersebut, Untuk lebih jelasnya untuk pembuatan respon spektra dapat dilihat pada gambar berikut:

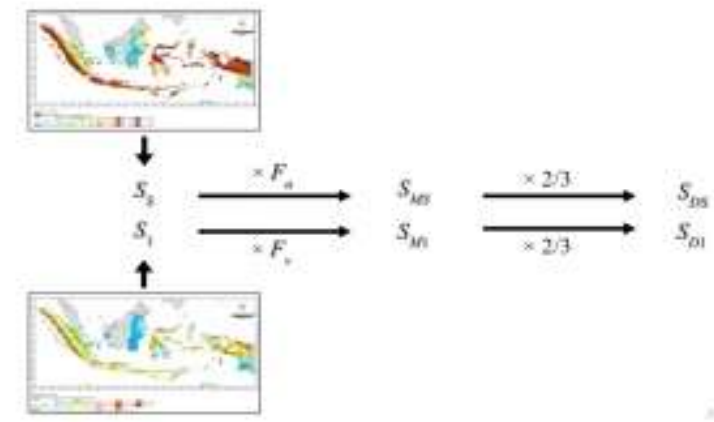

Gambar 1. Proses Pembuatan Spektrum Respons Desain.

Nilai keofesien situs yang umumnya juga dikenal sebagai faktor amplifikasi untuk periode pendek Fa dan untuk periode 1 detik Fv mangalami perubahan SNI-031726-2019 dengan mengadopsi dari hasil dari Pacific Earthquake Engineering Research (PEER) yang sedikit berbeda dengan yang ditetapkan dalam ASCE 7-16. Hal ini untuk menghihndari keharusan melakukan analisis respons spesifik SS $>1 \mathrm{~g}$, dan nilai percepatan respons spektral $\mathrm{S} 1>0.2 \mathrm{~g}$, seperti yang disyaratkan dalam ASCE 716. Menurut ASCE 7-16, yang didefinisikan sebagai batuan dasar (bed rock) bukan lagi dikelas situs tanah SB, melainkan di antara kelas situs SB an SC. Perlu dicatat bahwa pada MCER yang disajikan dalam gambar 1 telah disesuaikam dengan kriteria ini. Besarnya, berbeda dengan SNI-03-1726-2012, klasifikasi Ss ditambah dengan > 1,5 dan klasifikasi S1 ditambah dengan > 0,6, utuk mengambarkan daerah yang amat rawan gempa yang berada dekat dengan patahan atau sumber gempa. Terjadinya anomali di mana besarnya spekrum respons desain untuk kelas situs Tanah Keras (SC), Sedang (SD) dan Lunak (SE) tidak mengikat secara berurut seperti pada pakem lama diakibatkan oleh fluktuasi nilai Fa. Nilai keofesien Fa dan Fv, yaitu keofesien situs tanah untuk periode gempa panjang 1 detik. Keofesien Fa dan Fv sebelumnya diangap sudah terlalu lama tidak diperbarui (lebih baru 20 tahun) dan tidak sesuai lagi dengan hasil-hasil studi terbaru yang dilakukan oleh J. Steward, dkk. (Sutjipto, 2018).

Standar ini merupakan revisi dari SNI-03-2847-2012 yang mengacu pada 318M14 Building Code Requirements for Structural Concrete. Adapun dalam SNI-03-28472019, beberapa pasal mengenai struktur tahan gempa serta persyaratan desain durabilitas. Definisi kekuatan leleh dari baja tulangan mutu tinggi (fy > $420 \mathrm{Mpa}$ ) sama dengan yang ada didalam spesifikasi ASTM. Tulangan dan kawat non prategang harus berulir, batang atau kawat polos diperbolehkan digunakan sebagai tulangan spiral. Adapun kekuatan leleh tulangan dan kawat non prategang harus ditentukan dengan mengikuti salah satu poin dibawah ini: a) Metode offset dengan menggunakan offset sebesar $0,2 \%$; dan b) Titik leleh dengan menggunakan metode penghentian gaya (halt of proce) dengan catatan tulangan atau kawat non prategang memiliki titik leleh yang jelas.

Berdasarkan peraturan terbaru, tulangan longitudinal ulir non prategang yang menahan momen akibat beban gempa, gaya aksial, atau keduannya pada rangka momen khusus dinding struktural khusus dan semua komponen dari dinding struktural khusus termasuk balok kopel dan pilar dinding harus memiliki mutu $420 \mathrm{MPa}$. 
Tulangan mutu $280 \mathrm{MPa}$ diizinkan apabila poin a dan c dibawah ini dipenuhi dan tulangan mutu 420 diizinkan bila ketiga poin dibawah ini terpenuhi. Kekuatan leleh aktual berdasarkan tes pabrik nilai Fy tidak lebih dari $125 \mathrm{MPa}$. Rasio dari kekuatan tarik aktual terhadap kekuatan leleh setidak-tidaknya sebesar 1,25. Perpanjangan minimum pada $200 \mathrm{~mm}$ harus bernilai sekurang-kurangnya $14 \%$ untuk batang dengan D10-D19, sekurang-kurangnya $12 \%$ untuk tulangan dengan ukuran D22-D36, dan sekurang-kurangnya $10 \%$ untuk tulangan dengan ukuran D43-D57.

Pada struktur gedung bertingkat umumnya terbagi atas dua bagian utama yaitu struktur atas dan struktur bawah. Dalam struktur atas gedung bertingkat, komponen utamanya meliputi kolom, balok, pelat, tangga, pengaku dan konstruksi atap. Tetapi pada penelitian ini konstruksi gedung yang ditinjau hanya sebatas balok, kolom dan plat saja. Pada struktur bangunan gedung, kolom berfungsi sebagai pendukung bebanbeban dari pelat dan balok, untuk diteruskan ke tanah dasar melalui fondasi (Asroni, 2010). Sifat dari bahan beton, yaitu sangat kuat untuk menahan tekan, tetapi tidak kuat (lemah) untuk menahan tarik. Oleh karena itu, beton dapat mengalami retak jika beban yang dipikulnya menimbulkan teganga tarik yang melebihi kuat tariknya. Pelat lantai adalah komponen struktural bangunan yang memiliki dimensi tertentu untuk menyalurkan beban mati dan beban hidup di atasnya yang kemudian disalurkan kepada balok. Pada umumnya komponen penyusun plat lantai terdiri dari beton bertulang, di mana digunakan tulangan positif pada daerah tarik dan tulangan negatif pada daerah tarik dan tulangan negatif pada daerah tekan (Purba, 2014).

\section{B. Metodologi Penelitian}

Berikut merupakan gambaran alur metode penelitian yang dapat dilihat pada Gambar 2:

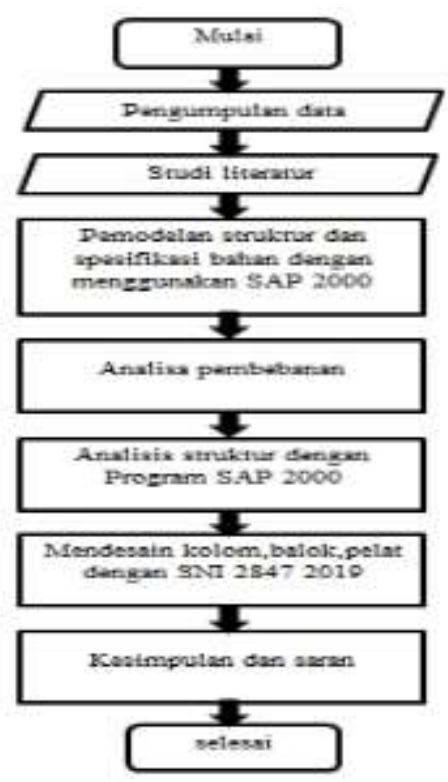

Gambar 2: Flow Chart Penelitian

\section{Hasil dan Pembahasan}

\section{Perpindahan Antar Lantai}

Nilai displacement merupakan hasil output analisis dari aplikasi SAP 2000. Nilai displacement maksimum pada arah $\mathrm{X}$ dan arah $\mathrm{Y}$ pada setiap lantai dapat dilihat pada ini: 


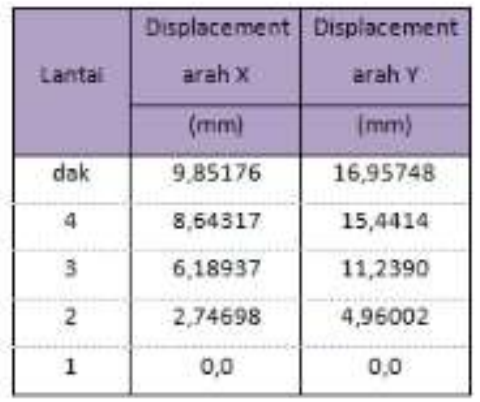

Tabel 1: Displacement antar lantai

\section{Gaya Geser Dasar (Base Shear)}

Nilai base shear akibat respon spektrum merupakan output dari analisis aplikasi SAP 2000 yang telah disesuaikan menggunakan persamaan yang terdapat di SNI-031726-2019 Tentang Tata Cara Perencanaan Ketahanan Gempa untuk Gedung dan Non Gedung, hasil dapat dilihat pada Tabel 2.

\begin{tabular}{|l|l|l|r|r|}
\hline Output & \multicolumn{1}{|c|}{ Case type } & Step type & GlobalFX & GlobalFY \\
\hline EX & LinRespSpec & Max & 5067,65 & 551,877 \\
\hline Ey & LinRespSpec & Max & 786 & 5074,786 \\
\hline & & & - & $7,958 \mathrm{E}-$ \\
EX static & LinStatic & & 5053,304 & 13 \\
\hline & & & $-1,277 \mathrm{E}-$ & - \\
EY static & LinStatic & & 11 & 5053,292 \\
\hline
\end{tabular}

\begin{tabular}{|c|c|c|c|c|}
\hline arah & dinamik & statik & $100 \%$ statik & kontrol \\
\hline $\mathrm{X}$ & 5067,65 & 5053,304 & 5053,304 & OK \\
\hline $\mathrm{Y}$ & 5074,786 & 5053,292 & 5053,292 & OK \\
\hline
\end{tabular}

Tabel 2: Nilai Base Shear

\section{Simpangan Antar Lantai}

Penentuan simpangan antar lantai desain $(\Delta)$ harus dihitung sebagai perbedaan defleksi pada pusat massa ditingkat teratas dan terbawah yang ditinjau, batas simpangan lantai diatur dalam SNI-03-1726-2019 pasal 7.8.6 yang dimana hasilnya sudah terpenuhi dan dapat dilihat Tabel gempa yaitu:

$$
\Delta \mathrm{x}=\frac{(\delta 2-\delta 1) \mathrm{xCd}}{\mathrm{I}}<\Delta \mathrm{a}
$$

Dari hasil nilai displacement pada tabel 3 menjelaskan nilai Sx dan Sy merupakan hasil displacement yang didapat dari aplikasi SAP 2000 kemudian dilakukan perhitungan manual dan mendapatkan nilai $\mathrm{dx}$ dan dy dan di cek dengan nilai $\Delta$ Izin.

\section{Partisipasi Massa}

Berdasarkan SNI-03-1726-2019 pasal 7.9.1, untuk mendapatkan partisipasi ragam terkombinasi paling sedikit $90 \%$, nilai partisipasi massa merupakan hasil SAP 2000 dimana hasilnya telah terpenuhi dan dapat dilihat pada Tabel 3: 


\begin{tabular}{|c|c|c|c|c|c|}
\hline Outputcace & StepType & StepNum & Period & Sumux & SumuY \\
\hline Text & Text & Unitiess & Sec & Unitien: & Unitiess \\
\hline MODAL & Mode & 1 & 0,432273 & 0,00116 & 0,60475 \\
\hline MODAL & Mode & 2 & 0.289525 & 0.95608 & 0.62571 \\
\hline MODAL & Mode & 3 & 0,218716 & 0,99772 & 0,99176 \\
\hline MODAL & Mode & 4 & 0.133069 & 0.99772 & 0,99176 \\
\hline MODAL & Mode & s & 0,131008 & 0,99773 & 0,99177 \\
\hline MOQALL & Mode & 6 & 0,110685 & 0.99774 & 0.99177 \\
\hline MODAL & Mode & 7 & 0,09394 & 0,99774 & 0,99178 \\
\hline MODAL & Mode & 8 & 0,087734 & 0.99777 & 0,99178 \\
\hline MOOAL & Mode & 2 & 0,070331 & 0.99777 & 0,99182 \\
\hline MOOAL & Mode & 10 & 0.055153 & 0.99783 & 0.99163 \\
\hline MODAL & Mode & 11 & 0.020331 & 0.99954 & 0,99228 \\
\hline MODAL & Mode & 12 & 0,015012 & 0.99957 & 0,99733 \\
\hline
\end{tabular}

Tabel 3 Partisipasi Massa

\section{Desain Balok SRPMK SNI-03-2847-2019}

Desain balok SRPMK menurut SNI-03-2847-2019 menjelaskan beberapa persyaratan umum. Adapun balok yang akan di desain adalah Balok B1 yang berukuran 400X650 mm dan balok BA1 300X600 mm.

\subsection{Perhitungan Balok B1 (400 X 650)}

\subsubsection{Perhitungan Balok B1 (400 X 650)}

A.Syarat dimensi Penampang (pasal 18.6.2.1)

1.Bentang bersih $>4 d$

$\mathrm{d}=$ tinggi balok - selimut beton - diameter sengkang $-\mathrm{db} / 2$

$=650-40-13-19 / 2$

$=587,5 \mathrm{~mm}$

$=4 \times 587,5=2350 \mathrm{~mm}$

In $=7000-1 / 2$ ukuran kolom $(600)$

$=6700 \mathrm{~mm}$

Dari hasil perhitungan syarat 1 bahwa bentang bersih balok adalah $6700 \mathrm{~mm}$ lebih besar dari 4d = 2350 maka syarat pertama OK

2.Lebar penampang, harus sekurangnya nilai terkecil dari $0,3 \mathrm{~h}$ dan $250 \mathrm{~mm}$

$$
\begin{aligned}
& \mathrm{Bw}=400>250 \mathrm{~mm} \mathrm{OK} \\
& 0,3 \mathrm{~h}=195<400 \mathrm{~mm} \mathrm{OK}
\end{aligned}
$$

\section{Lebar balok < lebar kolom + 2(3/4 tinggi kolom)}

Lebar balok adalah $400 \mathrm{~mm}$ lebih kecil dari tinggi kolom yaitu 600 dan di tambah 2(3/4 tinggi kolom) dengan hasil 1575 mm maka syarat ketiga OK.

\section{B.Desain Tulangan Lentur Balok}

Untuk mendapatkan rasio tulangan $(\rho)$ dilakukan perhitungan dengan menggunakan data $\mathrm{Mu}$ yang didapatkan pada aplikasi SAP 2000. Setelah didapatkan jumlah tulangan pada masing-masing tumpuan dan lapangan maka dilakukan perhitungan kuat momen rencana $(\otimes \mathrm{Mn})$, hasil perhitungan dapat dilihat pada Tabel 4. 


\begin{tabular}{|c|c|c|c|c|c|c|c|c|c|}
\hline \multirow[t]{2}{*}{ Nama } & \multirow{2}{*}{$\begin{array}{l}\begin{array}{l}\text { Ukuran } \\
\text { baiok }\end{array} \\
\text { (mm) }\end{array}$} & \multirow[t]{2}{*}{ daerah } & \multirow[t]{2}{*}{ letak } & $\begin{array}{c}\text { luas } \\
\text { terpasang }\end{array}$ & a & c & od & $\mathrm{Mg}$ & $2 \mathrm{Mgn}$ \\
\hline & & & & $(\operatorname{mm} 2)$ & $(\operatorname{mm} 2)$ & $(\mathrm{mm} 2)$ & & $\mathrm{kNm}$ & $\mathrm{kNm}$ \\
\hline \multirow[t]{4}{*}{ B1 } & \multirow[t]{4}{*}{400.650} & \multirow[t]{2}{*}{ Tumpuan } & Atas & 1983,70 & 80,33 & 95,35 & 0,16 & 434,30 & 390,87 \\
\hline & & & Bawah & 1416,93 & 57,38 & 68,11 & 0,11 & 316,72 & 285,04 \\
\hline & & \multirow[t]{2}{*}{ lapangan } & Aas & 1133,24 & 45,90 & 54,48 & 0,09 & 255,98 & 230,38 \\
\hline & & & Bwah & 1700,31 & 68,85 & 81,73 & 0,14 & 376,15 & 338,54 \\
\hline
\end{tabular}

Tabel 4: Perhitungan kuat momen rencana

C. Design tulangan transversal balok B1

Sengkang didaerah lapangan (dari $1 / 4 \mathrm{~L}$ hingga $1 / 2 \mathrm{~L}$ dari tumpuan), Nilai $\mathrm{Vu}=$ 170,136 pada daerah $1 / 4 \mathrm{~L}$ hingga $1 / 2$ tumpuan lebih besar $Q$ Vc sehingga tulangan geser harus disediakan dengan menggunakan persamaan av/s maksimum seperti perhitungan pada daerah tumpuan dan dipakai nilai

$$
\frac{A v \min }{s}=\left(\quad \frac{0,35 \mathrm{bw}}{f_{y t}}\right)=0,35
$$

sehingga jarak sengkang dan tulangan pada daerah lapangan dipakai D10 - 250 . Desain balok B1 dengan menggunakan persyaratan peraturan SNI-03-2847-2019 telah memenuhi syarat yang diatur dalam peraturan tersebut dimulai dari dimensi, desain tulangan serta perhitungan kuat momen rencana $(\propto \mathrm{Mn})$, dimana detail balok B1 dapat dilihat pada Gambar 3.
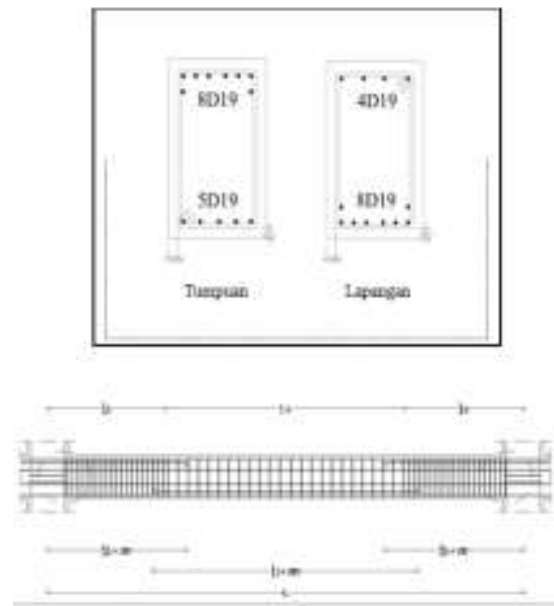

Gambar 3 : Detail Penulangan Balok B1

\subsection{Perhitungan Kolom K1 (600 X 600)}

1. Syarat dimensi penampang

a.Dimensi terkecil penampang

Dimensi terkecil penampang > dimensi minimum balok $=600 \mathrm{~mm}>300 \mathrm{~mm} \mathrm{OK}$

b. perbandingan $\mathrm{b} / \mathrm{h}$

$\mathrm{b} / \mathrm{h}>0,4=600 / 600>0,4 \mathrm{OK}$

2. Desain tulangan lentur Kolom

As perlu $=360000 \mathrm{~mm} 2$ (hasil SAP 2000) dipakai tulangan 12D25. Perhitungan kuat lentur nominal kolom K1. Berdasarkan perhitungan diagram interaksi kolom K1 dapat dilihat pada gambar berikut: 


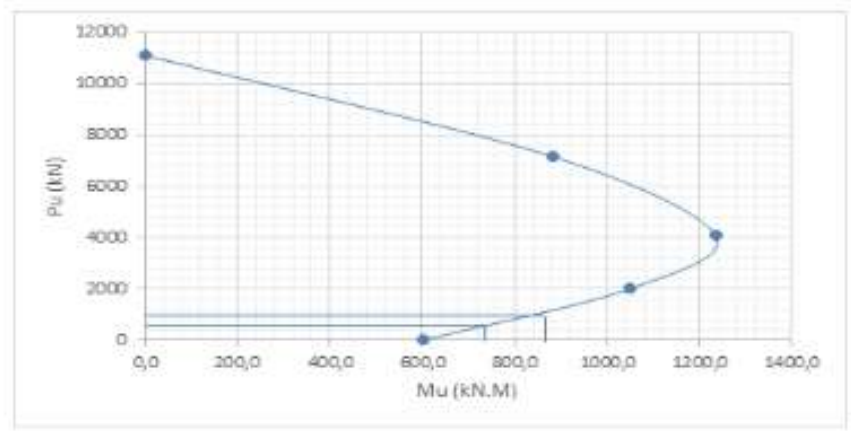

Gambar 4: Diagram interaksi kolom K1

$\mathrm{Mn}=850 \mathrm{kN} \cdot \mathrm{m}>\mathrm{Mu}=100,331 \mathrm{kN}$.m. Cek kolom kuat balok lemah (strong coloumn weak beam)

$$
\begin{aligned}
& P_{u \text { kolom bawah }}=1132 \mathrm{kN} \rightarrow M_{n c^{b}}=850 \mathrm{kN} \cdot \mathrm{m} \\
& P_{u \text { kolom atas }}=681,7 \mathrm{kN} \rightarrow M_{n c^{a}}=730 \mathrm{kN} \cdot \mathrm{m} \\
& \sum \begin{array}{c}
M_{n c}=M_{n c^{b}}+M_{n c^{a}}>1,2 \sum M_{n b} \\
=850+7301,2 \sum(730) \\
=1580>913,928 \mathrm{kN} . \mathrm{m}
\end{array}
\end{aligned}
$$

Berdasarkan hasil perhitungan diagram interaksi, kolom K1 yang ditunjau masih aman karena $\mathrm{Mn}>\mathrm{Mu}$, serta kolom kuat balok lemah terpenuhi.

3. Desain tulangan transversal kolom

Untuk struktur dengan $\mathrm{Pu}<0,3 \mathrm{Ag}$ fc' luas penampang total tulangan sengkang persegi di ambil nilai terbesar. Setelah dilakukan perhitungan Kolom K1 dengan menggunakan persyaratan peraturan SNI-03-2847-2019 telah memenuhi syarat yang diatur dalam peraturan tersebut dimulai dari dimensi, desain tulangan serta perhitungan kuat momen rencana $(\otimes \mathrm{Mn})$, diamana detail kolom K1 dapat dilihat pada Gambar 5.

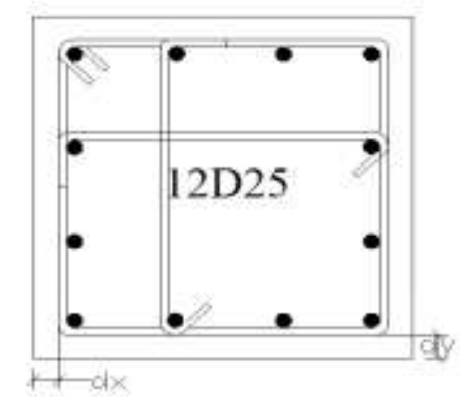

Gambar 5: Kolom K1

\subsection{Desain Pelat SRPMK SNI-2847-2019}

Desain pelat SRPMK menurut SNI-03-2847-2019. Adapun Pelat yang akan di desain :

menentukan nilai $a_{f m}$

$a_{f m}=\frac{a_{f i}+a_{f s}}{2}=18,16276235$

$\beta=\frac{8000-600}{4800-600}$

karena $a_{f m} 2,0$ maka nilai $h_{m i n}$

dicari dengan menggunakan persamaan 


$$
\begin{aligned}
h & =\frac{I_{n}\left(0,8+\frac{f y}{1,400}\right.}{36+9 \beta}=\frac{(7000-600) x\left(0,8+\frac{400}{1400}\right.}{36+9 \beta} \\
& =172,079>90 \mathrm{~mm} \mathrm{OK} \text { dipakai tebal plat } 120 \mathrm{~mm}
\end{aligned}
$$

Plat lantai pada gedung IRNA direncanakan menggunakan beton bertulang dengan sistem 2 arah ( $\mathrm{x}$ dan $\mathrm{y}$ ) atau 4 tumpuan sejajar. Plat lantai dianggap terjepit penuh pada keempat sisinya, setelah dihitung tebal plat $120 \mathrm{~mm}$. Perhitungan analisa mekanika pelat digunakan metode keofesien momen, perhitungan dilakukan pada plat $\mathrm{S} 1$. Dalam perhitungan didapatkan untuk pelat S1 dengan tipe ukuran A1,A2,A3 dan A4 dipakai tulangan diameter 10 dengan jarak $150 \mathrm{~mm}$

\section{Penutup}

Hasil penelitian ini menjelaskan bahwa perubahan pemodelan Rumah Sakit Umum Daerah Pasaman Barat ini memenuhi persyaratan terhadap desain gempa SNI03-1726-2019 dimana daerah tersebut jika dilihat dari perilaku struktur yang meliputi perpindahan antar lantai, gaya geser dasar, dan simpangan antar lantai nya. Hasil desain dari balok, kolom dan pelat setelah di desain ulang dengan SNI-03-2847-2019 untuk ukuran dimensi sudah memenuhi persyaratan, akan tetapi untuk tulangan lentur dan tulangan geser yang didapat setelah didesain mengalami perubahan seperti contoh pada Balok B1 pada kondisi awal dipakai tulangan 10D19 dan setelah didesian ulang dipakai 8D19.

\section{Daftar Pustaka}

Arifin, Z., Suryadi., Sebayang, S. (2015). Analisis Struktur Gedung POP Hotel Terhadap Beban Gempa Dengan Metode Pushover Analisis. JRSDD edisi September Vol 3 No 3 Hal :427-440 (ISSN: 2003-0011).

Bambang.,Afif, M. (2017). Kriteria Dasar Struktur Bangunan Tahan Gempa. Universitas 17 Agustus 1945 Semarang.

Fauziah, R. (2015). Studi Perbandingan Pembebanan gempa Statik Ekuivalent dan Dinamik Time History pada Gedung Bertingkat Yogyakarta. Jurnal Ilmiah Semesta Teknika Vol. 18, No.2 Hal 190-199.

Febrian, D.B., Budi, A.S., Sambowo.K.A. (2014). Evaluasi Kinerja Gaya Gempa Pada Gedung Bertingkat Dengan Analisis Respon Spektrum Berdasarkan Base Shear, Dispalacement, Dan Drift Menggunakan Software Etabs (Studi Kasus : Hotel Di Daerah Karanganyar). e-Jurnal Matriks Teknik Sipil Vol.1 No 2.

Hermanto, A., Widyarti, M., Fauzan, M. (2012). Analisis Struktur Bangunan Apartemen Grand Emerald Kelapa Gading Jakarta Utara Menggunakan Peta Gempa 2002 Dengan Anlisis Statik Equivalent. Institut Teknologi Pertanian Bogor.

Saputra, A., Firmanto, A. (2017). Analisis Struktur Rumah Sakit Pemata Cirebon. UNSWAGATI Cirebon. ISSN 2085:8744.

SNI 03-1726-2019 tentang tata cara perencanaan ketahanan gempa untuk struktural bangunan gedung dan non gedung. Jakarta.

RSNI 03-1727-2020. tentang beban minimum untuk perancangan bangunan gedung dan struktur lain. Jakarta.

SNI 03-2847-2019.tentang persyaran beton struktural untuk bangunan gedung. Jakarta. 